\title{
Development of transfersomal emulgel to enhance the permeation of berberine chloride for transdermal delivery
}

\author{
Fitria Mayangsari, Silvia Surini*, Raditya Iswandana
}

Laboratory of Pharmaceutics and Pharmaceutical Technology Development, Faculty of Pharmacy, Universitas Indonesia, Depok, West Java, 16424, Indonesia.

\begin{tabular}{l}
\hline ARTICLE INFO \\
\hline Received on: $18 / 06 / 2021$ \\
Accepted on: $10 / 10 / 2021$ \\
Available Online: $05 / 02 / 2022$ \\
\\
\hline Key words: \\
Berberine chloride, \\
transfersomes, emulgel, \\
transdermal, in vitro penetration.
\end{tabular}

\section{INTRODUCTION}

Several drugs such as berberine chloride derived from natural ingredients are Mohsen currently being developed. Berberine chloride (BBR) is a natural isoquinoline alkaloid isolated from medicinal herbs such as Coptis chinensis, Coptis japonica Makino, Berberis aristate, Berberis vulgaris, and Rhizoma coptidis. In recent years, various BBR pharmacological activities such as anti-inflammatory, antimicrobial, antidiabetic, and anticancer have been discovered (Battu et al., 2010; Liu et al., 2016). Moreover, the oral administration of BBR had a low bioavailability of less than $1 \%$. During the passive permeation through the membrane, $56 \%$ of drug suffers from the P-glycoprotein (P-gP) efflux, while $43.5 \%$ has metabolism in the intestine because BBR is converted to dihydroberberine by nitroreductase bacteria through a reduction reaction (Feng et al., 2015; Shi et al., 2015; Wang et al., 2018). Therefore, oral administration of BBR requires a higher dose or

*Corresponding Author

Silvia Surini, Laboratory of Pharmaceutics and Pharmaceutical Technology Development, Faculty of Pharmacy, Universitas Indonesia, Depok, West Java, 16424, Indonesia.E-mail: silvia@farmasi.ui.ac.id repeated dosing, which causes gastrointestinal side effects such as diarrhea, flatulence, abdominal pain, and gastric lesions (Liu et al., 2016; Xia and Luo, 2015).

Although transdermal delivery can be an alternative route in the administration of BBR, drug delivery through this route has several limitations, such as a skin barrier, which limits permeation. Also, BBR has low permeability due to the presence of methoxy and ammonium quartener groups in its structure, as shown in Figure 1 (Li et al., 2017; Narade and Pore, 2019). This is in line with a study by Torky et al. (2018), which showed that the permeation ability of BBR gel into the skin was restricted and many drugs stayed on the skin surface.

An approach to enhance drug absorption across the skin is through the use of vesicles such as transfersomes. Meanwhile, transfersomes are ultradeformable vesicles that consist of phospholipids and surfactants as the main components. Phospholipon 90G is used in the manufacturing of vesicles such as liposomes. This phospholipid contains $2 \%$ unsaturated fatty acids such as oleic, linoleate, and linolenic that increase skin penetration (Joshi et al., 2018). Generally, the edge activators used are a nonionic single-chain surfactant that destabilizes the lipid bilayer and increases the fluidity and elasticity of the transfersomes. 


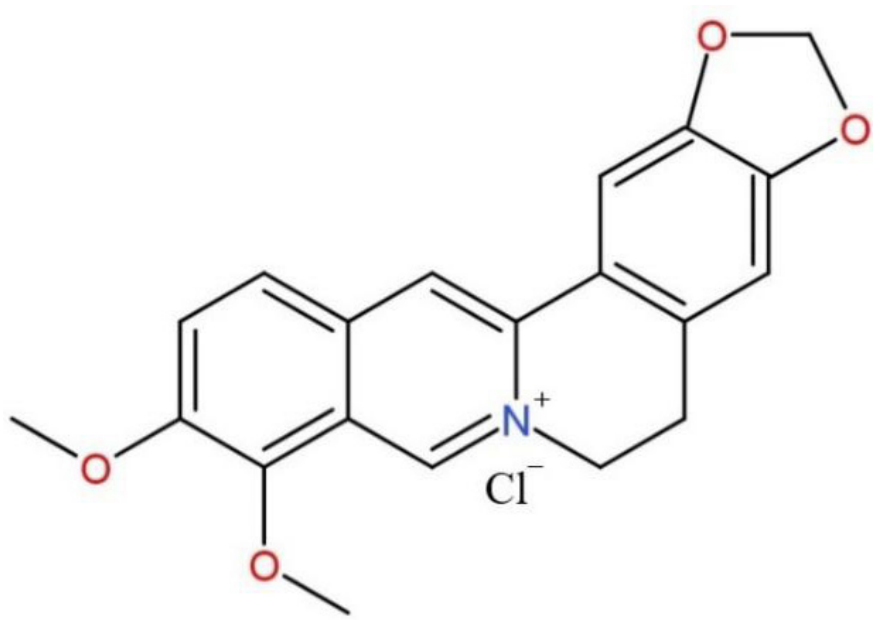

Figure 1. Structure of berberine chloride.

Furthermore, flexibility on transfersomes can reduce the risk of damage to the vesicles in the skin (El-Zaafarany et al., 2010). The flexibility of transfersomes membranes depends on the proper ratio between all materials (Bibi et al., 2017; Kumavat et al., 2013). The type and amount of surfactant used also to determine the stability and permeability of transfersomes (Ascenso et al., 2014). Since the transfersomes structure is similar in the body's biological membrane, it can be used as a drug carrier (Lu et al., 2014). In previous studies, transfersomes were formulated into an emulgel to ease the application on the skin, in addition to the emulgel properties of greaseless, easily spreadable, and removable (Ajazuddin et al., 2013; Phad et al., 2018). Therefore, this study aims to prepare transfersomal emulgel that contain BBR to enhance its penetration through skin membrane for transdermal delivery application.

\section{MATERIALS AND METHODS}

\section{Materials}

Berberine chloride was purchased from Rebaudiana Technology Development Limited (China). Berberine chloride standard was purchased from Sigma Aldrich (Singapore). Phospholipid such as Phospholipon 90G was provided as a gift sample from Lipoid S100 GMBH (Germany). Also, Sepigel 305 was purchased from Seppic (France), Tween 80 from Avantor (USA), and butylated hydroxytoluene (BHT) from Alpha Chemical (India). Other chemicals and solvents used were of analytical and high-performance liquid chromatography (HPLC) grade from Merck (Germany).

\section{Preparation of transfersomes}

The BBR transfersomes were prepared by the thin layer hydration method (Mohsen et al., 2010). All formulae of BBR transfersomes are shown in Table 1. The BBR, Phospholipon 90G, Tween 80, and BHT were dissolved into methanol and the organic solvent was vaporized by a rotary evaporator with a pressure of $227 \pm 5 \mathrm{mbar}$. The temperature of $40^{\circ} \mathrm{C} \pm 2^{\circ} \mathrm{C}$ was used, while the speed of the rotary evaporator was $150 \mathrm{rpm}$. A thin lipid layer was obtained on the flask walls and nitrogen gas was flown into the round bottom flask for 2 minutes. Furthermore, the flask was kept in a vacuum overnight for the residual organic solvent to evaporate
Table 1. Composition of various BBR transfersomes.

\begin{tabular}{ccccc}
\hline \multirow{2}{*}{ Materials } & \multicolumn{4}{c}{ Formulation (g) } \\
\cline { 2 - 5 } & $\mathbf{F 1}$ & $\mathbf{F 2}$ & $\mathbf{F 3}$ & $\mathbf{F 4}$ \\
\hline Berberine chloride & 0.83 & 0.83 & 0.83 & 0.83 \\
Phospholipon 90G & 12.00 & 11.33 & 10.67 & 10.00 \\
Tween 80 & 1.33 & 2.00 & 2.66 & 3.33 \\
Butylated hydroxytoluene & 1.67 & 1.67 & 1.67 & 1.67 \\
Phosphate buffer pH 7.4 & Up to 100 & Up to 100 & Up to 100 & Up to 100 \\
\hline
\end{tabular}

completely. Subsequently, the thin lipid layer was hydrated with a phosphate buffer solution $\mathrm{pH} 7.4$ under nonvacuum conditions at $40^{\circ} \mathrm{C} \pm 2^{\circ} \mathrm{C}$ with 100 glass beads. After the complete hydration of the thin lipid layer, the transfersomes suspension produced was transferred to the vial and the particle size was further reduced by extrusion through the polycarbonate membrane with a pore size of $200 \mathrm{~nm}$.

\section{Determination of particle size, PDI, and zeta potential}

The particles size, polydispersity index (PDI), and zeta potential were determined by the dynamic light scattering technique at a scattering angle of $173^{\circ}$ using a particle size analyzer by Zetasizer Nano. A total of transfersome suspension was diluted with $10 \mathrm{~mL}$ distilled water at $25^{\circ} \mathrm{C}$, while measurements were carried out in triplicate.

\section{Determination of entrapment efficiency (\% EE)}

The entrapment efficiency ( $\%$ EE) of BBR transfersomes was determined by indirect method with HPLC. Transfersomes suspension of $1 \mathrm{~mL}$ was centrifuged at 13,000 rpm for 15 hours at $4^{\circ} \mathrm{C}$. The supernatant which contained the free drug was separated carefully and the free drug in the supernatant was determined using the HPLC analysis with a UV detector at 345 $\mathrm{nm}$. The HPLC analysis was carried out using Agilent $\mathrm{C} 18$ column $(5 \mu \mathrm{m}, 4.6 \times 250 \mathrm{~mm})$; meanwhile, the mobile phase was a mixture of acetonitrile and $0.1 \%$ formic acid in water in the ratio of $70: 30 \mathrm{v} / \mathrm{v}$ with a flow rate of $1 \mathrm{ml} /$ minute at room temperature. In addition, the volume injection of the sample was $20 \mu 1$.

The entrapment efficiency of BBR was determined using the following equation:

$$
\text { Entrapment efficiency }(\%)=\frac{C \text { total }-C \text { free }}{C \text { total }}
$$

where $C_{\text {total }}$ is the total concentration of BBR in formulation and $\mathrm{C}_{\text {free }}$ is the concentration of free (unentrapped) BBR.

\section{Morphology of vesicle}

The morphology and structure of the transfersomes were analyzed using transmission electron microscopy (TEM). Subsequently, all samples were treated on copper grids and given $1 \%$ phosphotungstic acid for negative staining. All the samples were later dried and analyzed using TEM.

\section{Deformability index}

The deformability index was determined using the extrusion method. During the process, a total of $1 \mathrm{ml}$ of 
transfersomes suspension was passed through the polycarbonate membrane with a particle size smaller than the suspension in the mini extruder set. The volume of transfersomes suspension that passed through the polycarbonate membrane was recorded in milliliters. Furthermore, the size of the vesicle was measured using the dynamic light scattering technique. Meanwhile, the deformability index of transfersomes suspension was determined using the following equation (Surini et al., 2020):

$$
D=J\left(\frac{r v}{r p}\right)^{2}
$$

where $D$ is the deformability index, $J$ is the total volume of suspension that can pass through the membrane $(\mathrm{ml}), r v$ is the vesicle size of the transfersomes that can pass through the membrane (nm), and $r p$ is the membrane pore size (nm).

\section{Formulation emulgel containing the BBR transfersomes}

The composition of emulgel formulations containing BBR transfersomes is shown in Table 2. The transfersomal emulgel was formulated by dispersing Sepigel 305 in the water that contained $\mathrm{Na}_{2}$ EDTA. Subsequently, methylparaben and propylparaben were dissolved in propylene glycol, and polyethylene glycol 400 and the BBR-loaded transfersomes were added. The solution was finally poured into the emulgel base and stirred homogeneously.

\section{In vitro penetration study of $\mathrm{BBR}$ transfersomal emulgel}

In vitro penetration study was carried out using vertical Franz diffusion cells with Sprague Dawley female rat skin. The handling method of the experimental animals was approved by the Medical Research Ethics Committee of Faculty of Medicine Universitas Indonesia with registration No. 184/UN2.F1/ETIK/ PPM.00.02/2020. Moreover, the skin was placed into the diffusion chamber with the stratum corneum, the dermal side facing the donor, and the receptor compartments, respectively. Furthermore, the area of the diffusion cell was $1.76 \mathrm{~cm}^{2}$. The receptor compartment contains $16 \mathrm{~mL}$ of phosphate buffer $\mathrm{pH} 7.4$ and was stirred with a magnetic stirrer at a speed of $300 \mathrm{rpm}$ to ensure the homogeneity of BBR dissolved in all receptor fluids. The temperature of the receptor fluid was maintained at $37 \pm 0.5^{\circ} \mathrm{C}$ and the sample equivalent to $3 \mathrm{mg} \mathrm{BBR}$ was applied to the skin surface

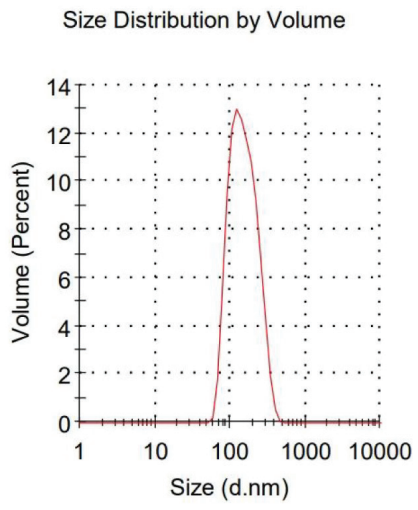

A

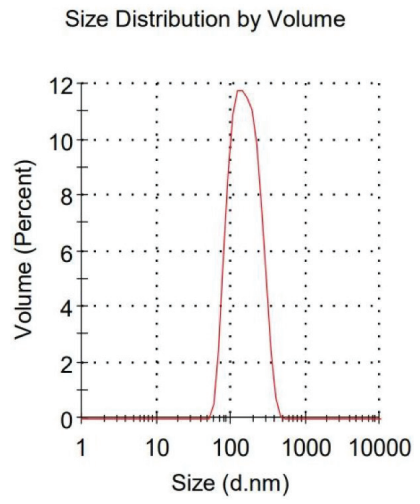

$\mathrm{C}$

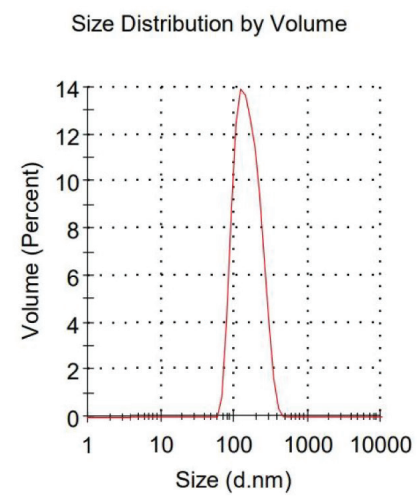

B

Size Distribution by Volume

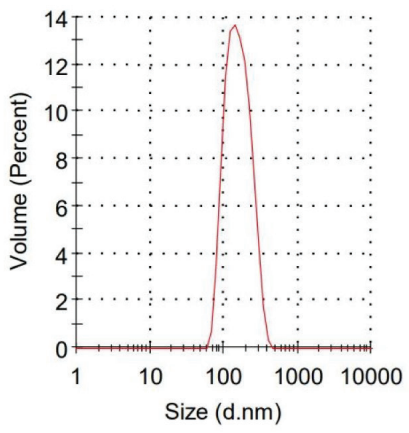

D
Figure 2. Size distribution of BBR transfersomes of F1 (A), F2 (B), F3 (C), and F4 (D).

in the donor compartment. Moreover, $1 \mathrm{ml}$ sample was withdrawn at predetermined intervals $(30,60,90,120,180,240,300,360$, 480 , and 720 minutes) and the same volume of phosphate buffer was replaced. The amount of BBR penetrated was evaluated using HPLC (Iswandana et al., 2018).

\section{Stability test}

The stability tests were carried out for 3 months on BBR transfersomal emulgel (F1-F4) and nontransfersomal emulgel

Table 2. Composition of emulgel containing BBR transfersomes.

\begin{tabular}{|c|c|c|c|c|c|}
\hline \multirow{2}{*}{ Materials } & \multicolumn{5}{|c|}{ Concentration $(\% \mathrm{w} / \mathrm{w})$} \\
\hline & EB & F1 emulgel & F2 emulgel & F3 emulgel & F4 emulgel \\
\hline BBR-loaded transfersomes & - & F1 equal to $0.3 \mathrm{BBR}$ & F2 equal to $0.3 \mathrm{BBR}$ & $\mathrm{F} 3$ equal to $0.3 \mathrm{BBR}$ & $\mathrm{F} 4$ equal to $0.3 \mathrm{BBR}$ \\
\hline Sepigel 305 & 8 & 8 & 8 & 8 & 8 \\
\hline $\mathrm{Na}_{2}$ EDTA & 0.10 & 0.10 & 0.10 & 0.10 & 0.10 \\
\hline Methyl paraben & 0.10 & 0.10 & 0.10 & 0.10 & 0.10 \\
\hline Propylparaben & 0.50 & 0.50 & 0.50 & 0.50 & 0.50 \\
\hline Distilled water & Up to 100 & Up to 100 & Up to 100 & Up to 100 & Up to 100 \\
\hline
\end{tabular}




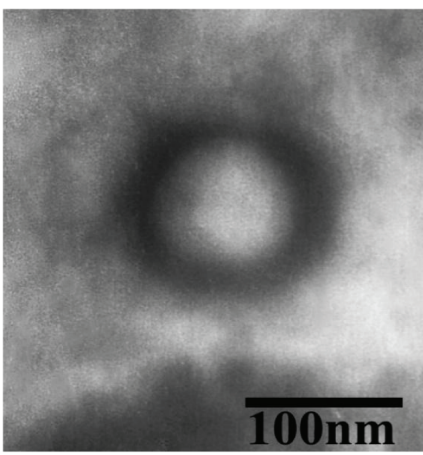

A

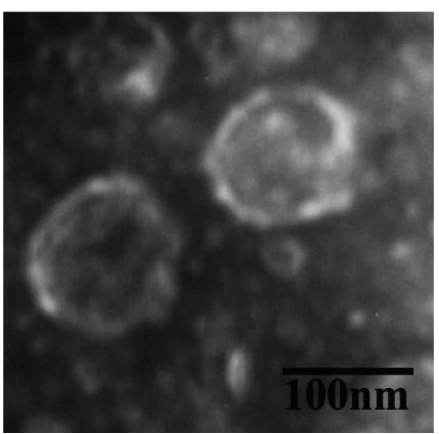

C

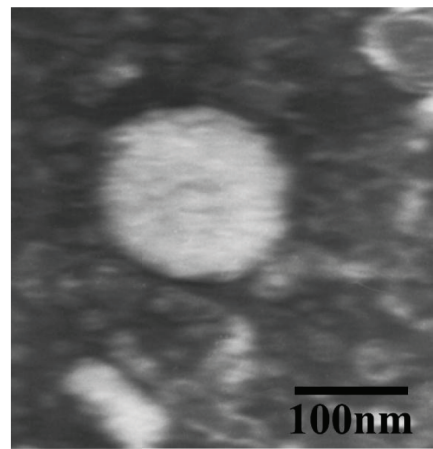

B

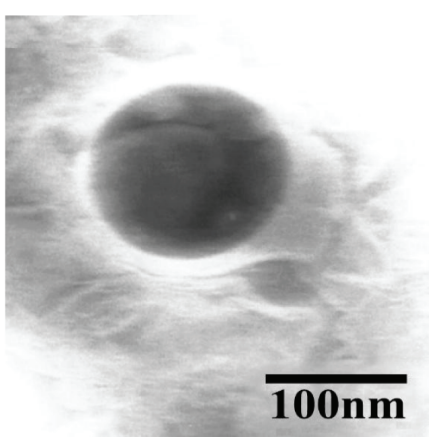

$\mathrm{D}$
Figure 3. Transmission electron microscope image of the BBR transfersomes of F1 (A), F2 (B), F3 (C), and F4 (D) with a magnification of $50.000 \times$.

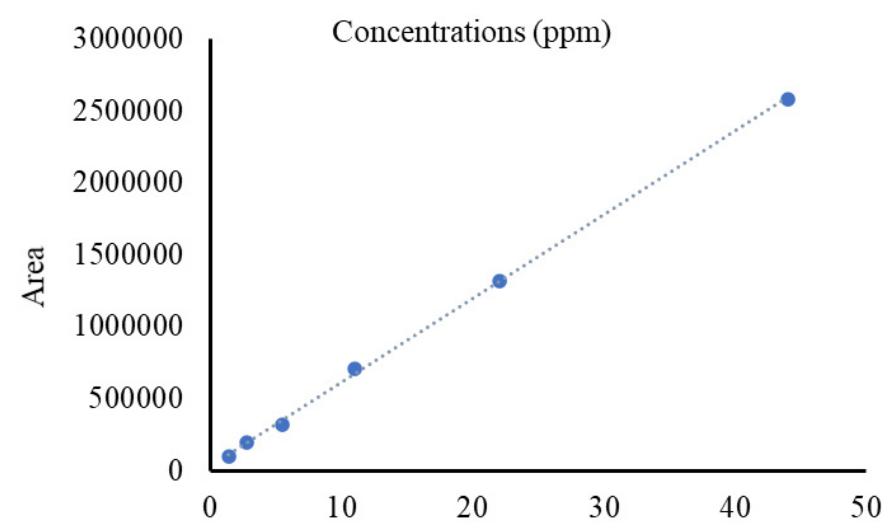

Figure 4. Calibration curves of BBR.

(EB), which were evaluated monthly for $\mathrm{pH}$ and $\mathrm{BBR}$ content. The storage temperature for the stability test was $5^{\circ} \mathrm{C} \pm 3^{\circ} \mathrm{C}$ and $25^{\circ} \mathrm{C} \pm 2{ }^{\circ} \mathrm{C}$, respectively.

\section{RESULTS AND DISCUSSION}

\section{Characterization of transfersomes}

\section{Particle size, PDI, and zeta potential}

Based on $Z_{\text {average }}$, the vesicle size of the four formulae was smaller than $200 \mathrm{~nm}$. When the particle size ranged from 10 to $200 \mathrm{~nm}$, it penetrated through the transfollicular route (Singh et al., 2017).

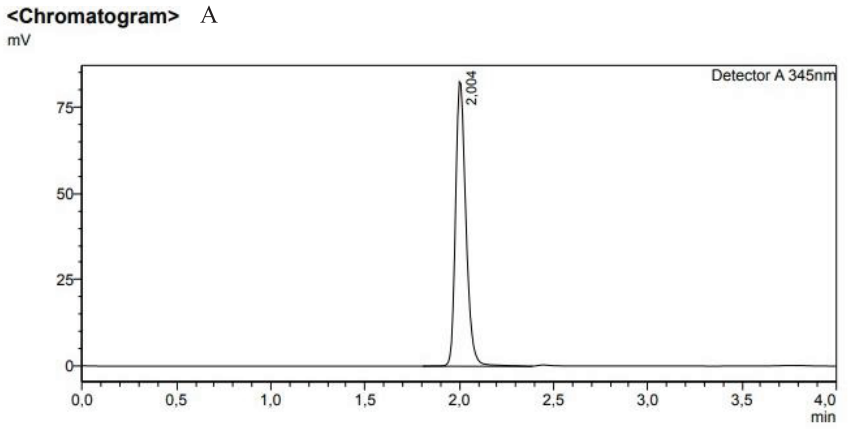

$<$ Chromatogram> B

$\mathrm{mV}$

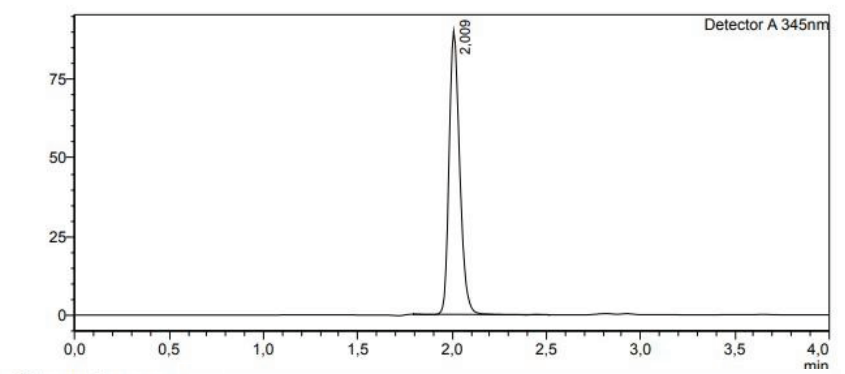

$<$ Chromatogram $>\mathrm{C}$

$\mathrm{mV}$

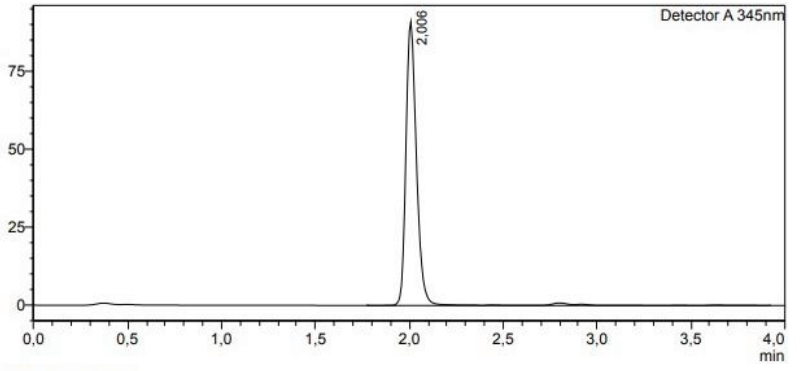

$<$ Chromatogram $>\mathrm{D}$

$\mathrm{mV}$

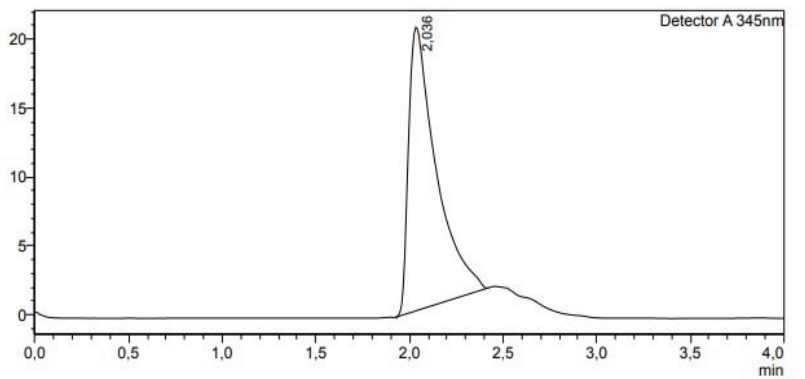

$<$ Chromatogram> E

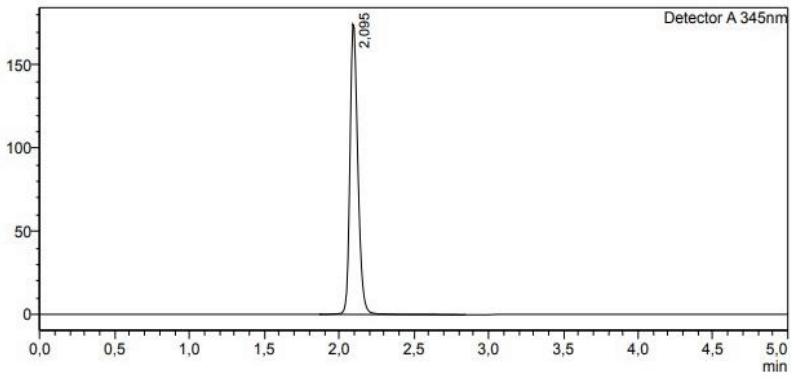

Figure 5. Representative HPLC chromatograms of (A) standard BBR, (B) BBR emulgel, (C) BBR transfersomal emulgel, (D) BBR transfersomes, and (E) free drug transfersomes. 
Although the transfersomes also pass through the intercellular route, they were elastic to pass through the stratum corneum pores which were much smaller than their size. The order of the transfersomes formula from the smallest particle size was $\mathrm{F} 1<\mathrm{F} 2<\mathrm{F} 3<\mathrm{F} 4$, as shown in Table 3 . Also, the ratio of surfactant and phospholipid concentrations slightly affected the particle size. Meanwhile, the particle size distribution of BBR transfersomes is shown in Figure 2.

The PDI values of the four transfersome formulae were satisfactory. According to Surini et al. (2020) and Danaei et al. (2018), PDI values less than 0.3 indicated that the particle size distribution of the vesicles is homogeneous and acceptable. Moreover, the PDI of the BBR transfersomes is shown in Table 3. This result showed that all formulae had high size homogeneity because the IPD value was less than 0.2 .

Out of the four transfersomes formulae, the $F 2$ transfersomes gave an adequate vesicles' dispersion, since its zeta potential was more than $-30 \mathrm{mV}$ as shown in Table 3 . These studies have shown that a good suspension has a zeta potential value that is more positive than $+30 \mathrm{mV}$ or negative than $-30 \mathrm{mV}$ (Leonyza and Surini, 2018). Meanwhile, the total charge on the vesicle surface was obtained by combining the lipid and surfactant charges in the formula. During the formation of transfersomes, a phosphate buffer solution of $\mathrm{pH} 7.4$ was used as a hydrating medium for the phosphatidylcholine to carry a negative charge. The zwitterion phospholipid used has a lower isoelectric point than the $\mathrm{pH}$ of the buffer solution (ElGizawy et al., 2020; Trivedi et al., 2021). Furthermore, $15 \%$ of anionic surfactants such as Tween were added to the composition giving a negative charge (Tawfeek et al., 2020).

\section{Morphology of vesicle}

The vesicle morphology of the F1-F4 transfersomes formula is shown in Figure 3. Based on the morphology, the transfersomes had a spherical shape and unilamellar with a size range of 100-200 nm, which showed that the extrusion process successfully reduced the size. Furthermore, the form and structure of the vesicles were affected by the manufacturing process of transfersomes. The temperature in the hydration medium also affected the formation of vesicles. Similarly, the volume of the phosphate buffer $\mathrm{pH} 7.4$ and the duration of the hydration process of the lipid film also affected the structure of the vesicles.
Table 4. The entrapment efficiency of the transfersomes formulation.

\begin{tabular}{cc}
\hline Formulation & Entrapment efficiency (\%) \\
\hline F1 & $89.51 \pm 1.42$ \\
F2 & $93.97 \pm 0.31$ \\
F3 & $88.64 \pm 1.31$ \\
F4 & $90.95 \pm 0.26$ \\
\hline
\end{tabular}

All values are represented as mean $\pm \mathrm{SD}(n=3)$.

\section{Entrapment efficiency (\% EE)}

The entrapment efficiency (EE\%) was an essential factor that needs to be optimized in transfersomes formulations. The BBR contents were evaluated by the HPLC method with a retention time of 2 minutes. Meanwhile, the amount of BBR in the sample was measured using the BBR standard curve with the regression equation of $y=58249 x+29254, r=0.9995$ as shown in Figure 4 and their chromatograms are shown in Figure 5.

As shown in Table 4, the transfersomes F2 had the highest entrapment efficiency compared to other formulae. These results showed that the optimal formulation condition for entrapment efficiency was a ratio of phospholipid:Tween 80 of $85: 15$, which was in line with the studies by Tawfeek et al. (2020) and El-Zaafarany et al. (2010). The use of a 15\% edge activator provided the best vesicle preparation with high entrapment efficiency values. Moreover, the entrapment efficiency was reduced by increasing the surfactant concentration from $15 \%$ to $25 \%$, because the use of high surfactant concentrations caused less vesicle leakage. In addition, it was also affected by the volume of the hydration medium and the duration of the lipid film hydration process.

\section{Deformability index}

In this study, all the transfersomes formulae gave good deformability. The transfersomes dispersion fluid completely passed through the polycarbonate membrane and the highest deformability index was F4 transfersomes, as shown in Table 5. These results showed that the deformability index was affected by the ratio of surfactant concentrations. This is in line with the study by El-Zaafarany et al. (2010) which showed that the highest deformability index was from the use of $25 \%$ surfactant concentration. Although surfactants can destabilize the lipid bilayer and increase fluidity and elasticity, the application of

Table 3. Particle size distribution, polydispersity index, and zeta potential of the transfersomes.

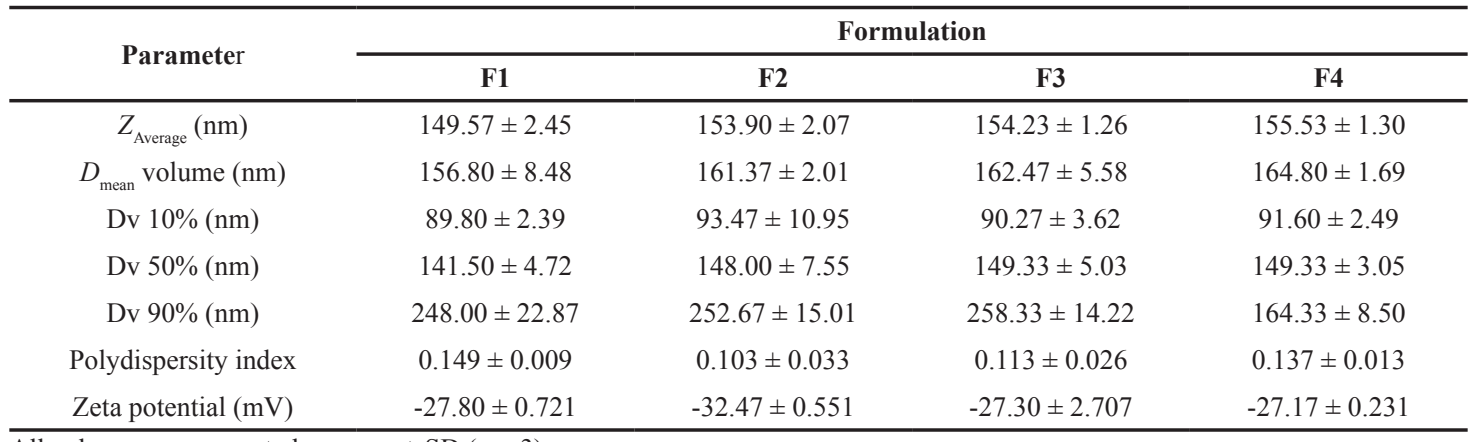

All values are represented as mean $\pm \mathrm{SD}(n=3)$. 


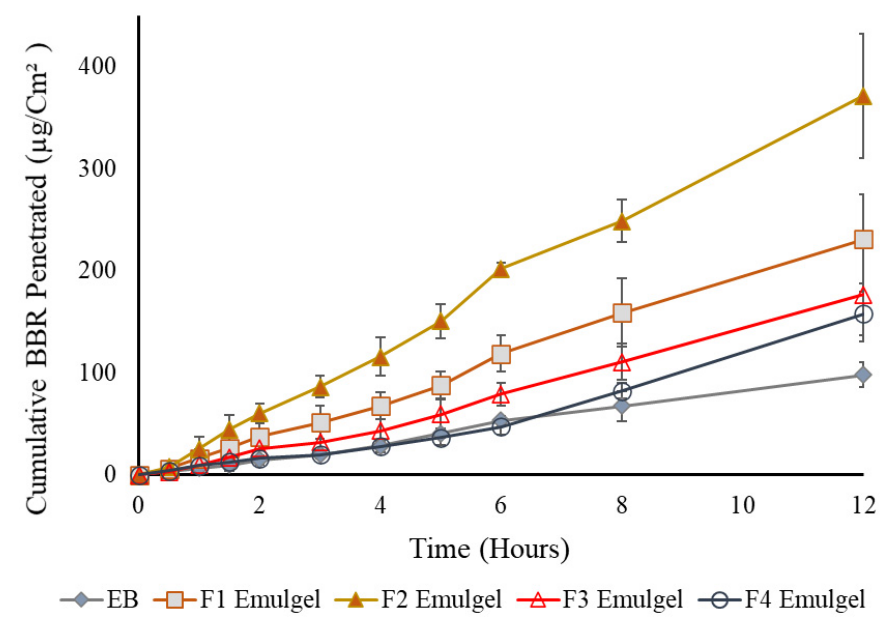

Figure 6. The cumulative berberine chloride penetrated from transfersomal emulgel and nontransfersomal emulgel.

EB, nontransfersomal emulgel BBR; F1 emulgel, emulgel containing BBR transfersomes F1; F2, emulgel, emulgel containing BBR transfersomes F2; F3 emulgel, emulgel containing BBR transfersomes F3; and F4 emulgel, emulgel containing BBR transfersomes F4.

high surfactant concentrations caused less vesicle leakage, which affects the drug released. Hence, the use of surfactants with low concentrations caused stiff vesicles and reduced their sensitivity to water activity gradients.

\section{Evaluation of BBR transfersomal emulgels}

These results showed that all BBR emulgels were yellow, odorless, and not greasy and had good homogeneity. Furthermore, there were no visible coarse particles on the emulgels. The $\mathrm{pH}$ values of transfersomal emulgels were about 7.4, while nontransfersomal emulgel was 6.2. This is due to the phosphate buffer solution of $\mathrm{pH} 7.4$ in the transfersomes formulation, which affected the emulgel base $\mathrm{pH}$. In addition, the measurement of BBR content in each transfersomal emulgel ranged from $98.34 \%$ to $105.87 \%$.

\section{In vitro penetration study of $\mathrm{BBR}$ transfersomal emulgel}

The in vitro penetration study of BBR transfersomal emulgel is shown in Figure 6. These results showed that the initial BBR released from the emulgels occurred within the first 30 minutes. This occurred because the unentrapped BBR in the vesicle surface passed through the skin earlier, while the entrapped BBR diffused slowly from the vesicle and penetrated through the

Table 5. Deformability index of the transfersomes formulation.

\begin{tabular}{cccc}
\hline Formulation & $\begin{array}{c}\text { Volume of } \\
\text { extruded } \\
\text { transfersomes } \\
(\mathbf{m l})\end{array}$ & $\begin{array}{c}\text { Particle size } \\
\text { after extrusion } \\
(\mathbf{n m})\end{array}$ & $\begin{array}{c}\text { Deformability } \\
\text { index }\end{array}$ \\
\hline F1 & 1.00 & $117.8 \pm 0.64$ & $1.388 \pm 0.015$ \\
F2 & 1.00 & $130.3 \pm 1.50$ & $1.698 \pm 0.039$ \\
F3 & 1.00 & $123.1 \pm 3.29$ & $1.516 \pm 0.082$ \\
F4 & 1.00 & $145.6 \pm 2.45$ & $2.121 \pm 0.071$ \\
\hline
\end{tabular}

All values are represented as mean $\pm \mathrm{SD}(n=3)$.
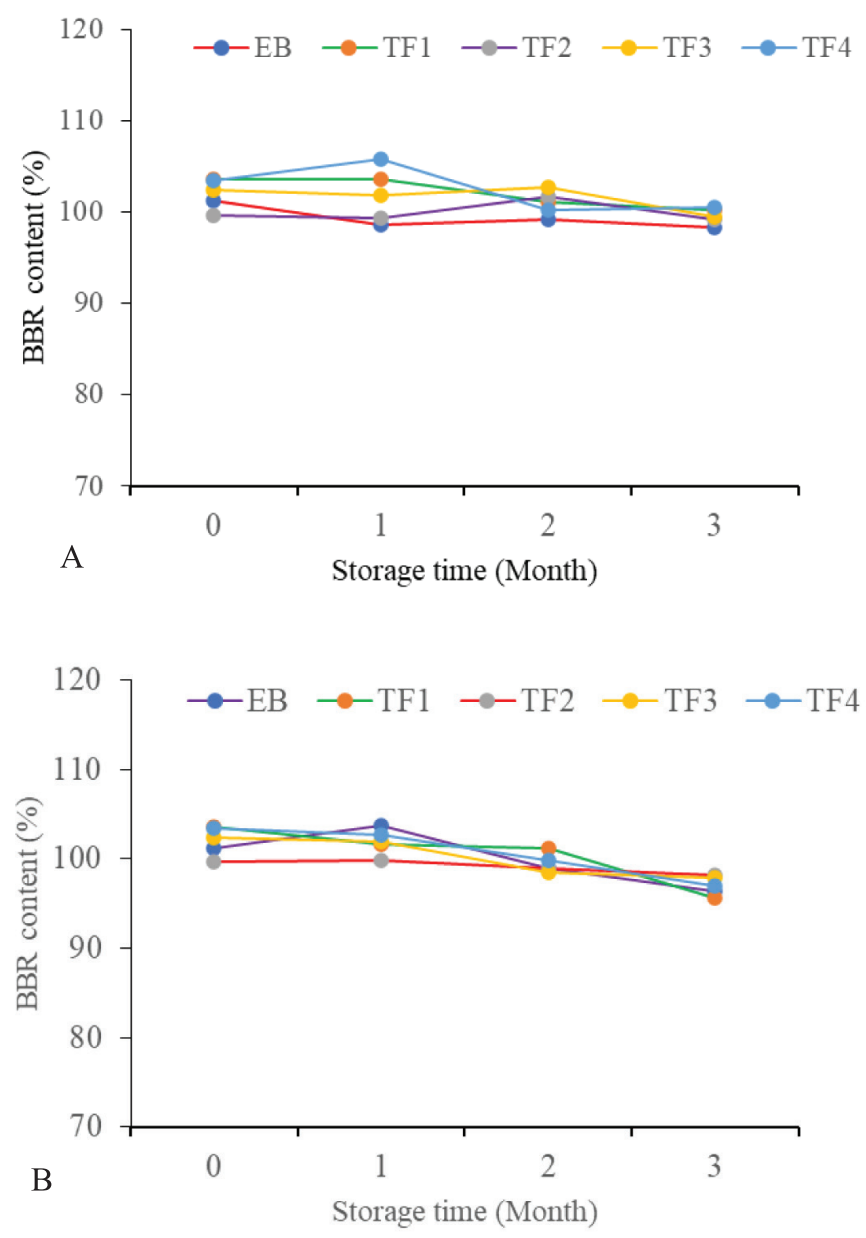

Figure 7. Stability data from $\mathrm{BBR}$ transfersomal emulgel under storage at $5^{\circ} \mathrm{C}$ $\pm 3^{\circ} \mathrm{C}(\mathrm{A})$ and $25^{\circ} \mathrm{C} \pm 2^{\circ} \mathrm{C}$ (B) for 3 months.

skin. This result was in line with the study by Balata et al. (2020), which stated that the initial rapid release phase was observed from 0 to 4 hours after transfersomes were applied.

Figure 6 shows that the BBR penetration of the transfersomal emulgel was more remarkable than the nontransfersomal emulgel (EB). Furthermore, the transfersomal emulgel F2 has the highest cumulative amount of BBR penetration, while the BBR emulgel without transfersomes gave the lowest for 12 hours, which is in line with the study by El-Zaafarany et al. (2010). This was influenced by differences in permeability between transfersomal emulgel and nontransfersomal emulgel. As previously stated, transfersomes have ultradeformable properties from Tween that caused its BBR to penetrate the skin. Moreover, Tween 80 has a longer carbon chain $(\mathrm{C} 18)$ with one double bond on the lipophilic tail, and there was no structure like steroids. Therefore, Tween 80 was incorporated with the lipid bilayer to form more permeable transfersomes (Balata et al., 2020; Lei et al., 2013).

The calculated enhancement ratio of total BBR penetrated from each preparation for EB, F1 emulgel, F2 emulgel, F3 emulgel, and F4 emulgel was 1.0, 2.4, 3.8, 1.8, and 1.6-fold, respectively. This occurred because the entrapment efficiency of the F2 transfersomes exceeded another formula, which showed that the cumulative amount of BBR penetration was affected by the entrapment efficiency of the transfersomes. Although F4 
Table 6. Flux value and permeability coefficient from formulation tests.

\begin{tabular}{|c|c|c|}
\hline Formula & Flux ( $\mu \mathrm{g} / \mathrm{cm}^{2} /$ hour $)$ & $\mathrm{Kp} \times 10^{-3}(\mathrm{~cm} / \mathrm{hour})$ \\
\hline EB & $8.503 \pm 1.359$ & $2.834 \pm 0.453$ \\
\hline F1 emulgel & $19.780 \pm 3.925$ & $6.593 \pm 1.308$ \\
\hline F2 emulgel & $31.784 \pm 5.014$ & $10.595 \pm 1.671$ \\
\hline F3 emulgel & $14.910 \pm 2.701$ & $4.970 \pm 0.900$ \\
\hline F4 emulgel & $12.591 \pm 1.538$ & $4.197 \pm 0.513$ \\
\hline
\end{tabular}

Kp: permeability coefficient.

All values are represented as mean $\pm \mathrm{SD}(n=3)$.

transfersomes had better deformability than the other formulae, the use of high surfactant concentrations caused less vesicle leakage, which affected drug released.

From Table 6, it can be seen that the flux and permeability coefficient were the highest for the F2 emulgel formula and the lowest for the EB formula. The F2 emulgel showed higher drug permeation through rat skin because the vesicle size is less than $200 \mathrm{~nm}$. Moreover, the ability of the transfersomes to deform is caused by the presence of surfactant components and phospholipids which enhance BBR permeation into the skin.

\section{Stability test}

The stability study of the transfersomal and nontransfersomal emulgels was carried out at $5^{\circ} \mathrm{C} \pm 3^{\circ} \mathrm{C}$ and $25^{\circ} \mathrm{C} \pm 2^{\circ} \mathrm{C}$ for 12 weeks. These results showed that all emulgels have no significant change in $\mathrm{pH}$ (data not shown) and met the specification of the BBR content within the range of $80 \%-120 \%$, as shown in Figure 7. This indicated that the long-term stability of the BBR transfersomal emulgel met the specification requirements after three months of storage. This is in line with the study by Elsheikh et al. (2018) which showed that BBR content has no significant changes at refrigeration for 6 months.

\section{CONCLUSION}

The ratio of phospholipids to surfactants has an influence on the physicochemical properties of BBR-loaded transfersomes, especially on entrapment efficiency and deformability index. Based on this study, the optimum ratio of phospholipids and surfactants to produce a satisfactory BBR transfersome was $85 \%$ $15 \%$. Furthermore, BBR penetration was highly enhanced by transfersomal emulgel compared to the nontransfersomal emulgel. This showed that the transfersomal emulgel is a promising vesicle for transdermal BBR delivery.

\section{ACKNOWLEDGMENT}

The authors are grateful to Universitas Indonesia for supporting this study through the PUTI Saintekes research grant with contract number NKB-2094/UN2.RST/HKP.05.00/2020.

\section{AUTHOR CONTRIBUTIONS}

All authors made substantial contributions to conception and design, acquisition of data, or analysis and interpretation of data; took part in drafting the article or revising it critically for important intellectual content; agreed to submit to the current journal; gave final approval of the version to be published; and agree to be accountable for all aspects of the work. All the authors are eligible to be an author as per the international committee of medical journal editors (ICMJE) requirements/guidelines.

\section{CONFLICTS OF INTEREST}

The authors report no financial or any other conflicts of interest in this work

\section{ETHICAL APPROVALS}

The handling method of the experimental animals was approved by the Medical Research Ethics Committee of Faculty of Medicine Universitas Indonesia with registration No. 184/UN2. F1/ETIK/ PPM.00.02/2020.

\section{PUBLISHER'S NOTE}

Publisher's Note: This journal remains neutral with regard to jurisdictional claims in published institutional affiliation.

\section{REFERENCES}

Ajazuddin, Alexander A, Khichariya A, Gupta S, Patel RJ, Giri TK, Tripathi DK. Recent expansions in an emergent novel drug delivery technology: emulgel. J Control Release, 2013; 171:122-32.

Ascenso A, Salgado A, Euleterio C, Praca FG, Bentley MV, Marques HC, Oliveira H, Santos C, Simoes S. In vitro and in vivo topical delivery studies of tretinoin- loaded ultradeformable vesicles. Eur J Pharm Biopharm, 2014; 88:48-55.

Balata GF, Faisal MM, Elghamry HA, Sabry SA. Preparation and characterization of ivabradine $\mathrm{HCl}$ transfersomes for enhanced transdermal delivery. J Drug Deliv Sci Technol, 2020; 60:101921.

Battu AK, Repka MA, Maddineni S, Chittiboyina AG, Avery MA, Majumdar S. Physicochemical characterization of berberine chloride: a perspective in the development of a solution dosage form for oral delivery. AAPS Pham Sci Tech, 2010; 11(3):1466-75.

Bibi N, Ahmed N, Khan GM. Chapter 21-Nanostructures in transdermal drug delivery systems. In: Andronescu A \& Grumezescu AM, ed. Nanostructures for Drug Delivery 1st edition. Elsevier Inc., pp 639-68, 2017. doi:10.1016/B978-0-323-46143-6.00021-X

Danaei M, Ataei DS, Davarani FH, Javanmard R, Dokhani A, Khorasani S, Mozafari MR. Impact of particle size and polydispersity index on the clinical applications of lipidic nanocarrier systems. Pharmaceutics, 2018; 10(57):1-17.

ElGizawy SA, Nouh A, Saber S, Kira AY. Deferoxamine-loaded transfersomes accelerates healing of pressure ulcers in streptozotocininduced diabetic rats. J Drug Deliv Sci Technol, 2020; 58:1-15.

Elsheikh MA, Elnaggar YSR, Hamdy DA, Abdallah OY. Novel cremochylomicrons for improved oral bioavailability of the antineoplastic phytomedicine berberine chloride: Optimization and pharmacokinetics. Int J Pharm, 2018; 535:316-24.

El-Zaafarany GM, Awad GAS, Holayel SM, Mortada ND Role of edge activators and surface charge in developing ultradeformable vesicles with enhanced skin delivery. Int J Pharm, 2010; 397:164-72.

Feng R, Shou JW, Zhao ZX, He CY, Ma C, Huang M, Fu J, Tan XS, Li XY, Wen BY, Chen X, Yang XY, Ren G, Lin Y, Chen Y, You XF, Wang Y, Jiang JD. Transforming berberine into its intestine-absorbable form by the gut microbiota. Sci Report, 2015; 5:12155.

Iswandana R, Chalista W, Sitepu ES. Formulation and penetration enhancement activity of sticks containing caffeine. J Appl Pharm Sci, 2018; 8(01):043-9.

Joshi A, Kaur J, Kulkarni R, Chaidhari R. In-vitro and ex-vivo evaluation of raloxifene hydrochloride delivery using nano-transfersome based formulations. J Drug Deliv Sci Technol, 2018; 45:151-8.

Kumavat SD, Chaudhari YS, Borole P, Duvvuri P, Bubera N, Shenghani K, Shah P, Mishra P. Transfersomes: a promising approach for transdermal drug delivery system. Asian J Pharm Sci Res, 2013; 3(5):1-17. 
Lei W, Yu C, Lin H, Zhou X. Development of tacrolimus-loaded transfersomes for deeper skin penetration enhancement and therapeutic effect improvement in vivo. Asian J Pharm Sci, 2013, 8:336-45.

Leonyza A, Surini S. Optimization of sodium deoxycholatebased transfersomes for percutaneous delivery of peptides and proteins. Int J Appl Pharm, 2019; 11(5):329-32.

Li YJ, Hu XB, Lu XL, Liao DH, Tang TT, Wu JY, Xiang DX. Nanoemulsion-based delivery system for enhanced oral bioavailability and caco-2 cell monolayers permeability of berberin hydrochloride. Drug Deliv, 2017; 24(1):1868-73.

Liu CS, Zheng YR, Zhang YF, Long XY. Research progress on berberine with a special focus on its oral bioavailability. Fitoterapia, 2016; 109:274-82.

Lu K, Xie S, Han S, Zhang J, Chang X, Chao J, Huang Q, Yuang Q, Lin H, Xu L, Shen C, Tan M, Qu S, Wang C, Song X. Preparation of a nano emodin transfersome and study on its anti-obesity mechanism in adipose tissue of diet-induced obese rats. J Transl Med, 2014; 12(72):1-14.

Mohsen AM, Salama A, Kassem AA. Development of acetazolamide loaded bilosomes for improved ocular delivery: preparation, characterization, and in vivo evaluation. J Drug Del Sci Tech, 2020; 59:101910.

Narade S, Pore Y. Optimization of ex vivo permeability characteristics of berberin in presence of quercetin using 32 full factorial design. J Appl Pharml Sci, 2019; 9(01):073-82.

PhadAR, Dilip NT, Ganapathy RS. Emulgel: Acomprehensive review for topical delivery of hydrophobic drugs. Asian J Pharm, 2018; 12(2):382-93.

Shi C, Tong Q, Fang J, Wang C, Wu J, Wang W. Preparation, characterization and in vivo studies of amorphous solid dispersion of berberine with hydrogenated phosphatidylcholine. Eur J Pharm Sci, 2015; $74: 11-7$.

Singh S, Verma D, Mirza MA, Das AK, Dudeja M, Anwer MK, Sultana Y, Talegaonkar S, Iqbal Z. Development and optimization of ketoconazole loaded nanotransfersomal gel for vaginal delivery using Box-Behnken design: In vitro, ex vivo characterization and antimicrobial evaluation. J Drug Deliv Sci Technol, 2017; 39:95-103.

Surini S, Leonyza A, Suh CW. Formulation and in vitro penetration study of recombinant human epidermal growth factor-loaded transfersomal emulgel. Adv Pharm Bull, 2020; 10(4):586-94.

Tawfeek HM, Abdellatif AAH, Aleem JAA, Hassan YA, Fathalla D. Transfersomal gel nanocarriers for enhancement the permeation of lornoxicam. J Drug Deliv Sci Technol, 2020; 56:101540.

Torky AS, Freag MS, Nasra MMA, Abdallah OY. Novel skin penetrating berberine oleate complex capitalizing on hydrophobic ion pairing approach. Int J Pharm, 2018; 549:76-86.

Trivedi R, Umekar M, Kotagale N, Bonde S, Taksande J. Design, evaluation and in vivo pharmacokinetic study of a cationic flexible liposomes for enhanced transdermal delivery of pramipexole. J Drug Deliv Sci Technol, 2021; 61:102313.

Wang H, Zhu C, Ying Y, Luo L, Huang D, Luo Z. Metformin and berberine, two versatile drugs in treatment of common metabolic diseases. Oncotarget, 2018; 9(11):10135-46.

Xia LM, Luo MH. Study progress of berberine for treating cardiovascular disease. Chron Diseas Transl Med, 2015; 1:231-5.

\section{How to cite this article:}

Mayangsari F, Surini S, Iswandana R. Development of transfersomal emulgel to enhance the permeation of berberine chloride for transdermal delivery. J Appl Pharm Sci, 2022; 12(02):048-055. 